\title{
Procedure Planned Time Point Name
}

National Cancer Institute

\section{Source}

National Cancer Institute. Procedure Planned Time Point Name. NCI Thesaurus. Code C117534.

The literal identifier of a planned point in time for a procedure. 